\title{
Modelling of streamflow in snow dominated Budhigandaki catchment in Nepal
}

\author{
H B Khatri ${ }^{1}$, M K JAIN ${ }^{2} *_{(\infty)}$ and $\mathrm{S}$ K JAIN ${ }^{3}$ \\ ${ }^{1}$ Ministry of Energy, Government of Nepal, Kathmandu 44600, Nepal. \\ ${ }^{2}$ Department of Hydrology, Indian Institute of Technology Roorkee, Roorkee 247667 , India. \\ ${ }^{3}$ National Institute of Hydrology, Roorkee 247667 , India. \\ *Corresponding author.e-mail: jain.mkj@gmail.com
}

MS received 3 August 2017; revised 15 December 2017; accepted 30 January 2018; published online 27 August 2018

This study has been envisaged to model streamflow runoff-contributed mostly by snowmelt from Budhigandaki catchment in Nepal. Available hydro-meteorological data have been collected from the Department of Hydrology and Metrology, Nepal. The MODIS Aqua (MYD10A2) and Terra (MOD10A2) 8 day maximum snow cover extent product have been used to derive the snow cover area (SCA) in the basin. The modeling of streamflow has been carried out using HEC-HMS and SRM models. The performance of these models have been evaluated by using three well known evaluation criteria NSE, $R^{2}$ and PEV (percentage error in volume). The values of NSE, $R^{2}$ and PEV were found to be 0.944, 0.944 and $-0.3 \%$ for SRM and $0.778,0.785$ and $-1.83 \%$ for HEC-HMS, respectively. Similarly, in validation period the average values of NSE, $R^{2}$ and PEV were found to be $0.811,0.816$ and $2.01 \%$ for SRM model and $0.773,0.777$ and $3.5 \%$ for HEC-HMS, respectively. Sensitivity analysis of the models revealed that constant loss rate is very sensitive parameters for HEC-HMS model, whereas runoff coefficient is found to be most sensitive parameters for SRM model. In comparison between two models SRM model has given slightly better simulation results compared to HEC-HMS model.

Keywords. Snowmelt; runoff; MODIS; snow cover area; snowmelt modeling; Himalaya.

\section{Introduction}

Estimation of streamflow from ungauged basin is very important for the planning of water resource projects in the basin. Most of the basins in the Himalayan region are ungauged due to highly rugged mountainous terrain, where it is very difficult to observe hydro-meteorological data and also it is not possible to do the measurement at every small catchment and at every location of the stream, however, great potential for development of hydropower projects exists in these catchments. Mathematical analysis or modeling of the streamflow assumes greater significance in such data deficit mountainous catchments for the planning of projects at a particular location to assess the availability of water. Many hydrological models have been developed to simulate the streamflow from a catchment. Selection of appropriate hydrological model for a catchment with no gauging station or with limited data is very challenging and important for the estimation of streamflow (Azmat et al. 2016).

Hydrological models which are capable to simulate runoff from rainfall input only, are found inefficient for prediction of daily streamflow in 


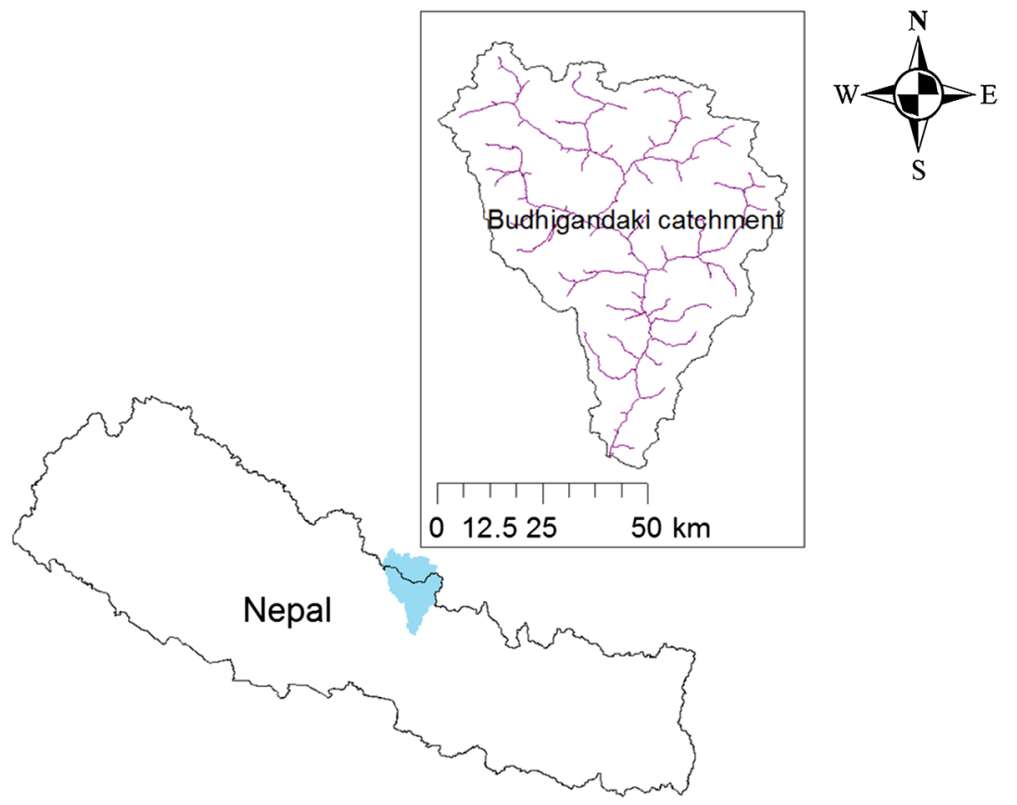

Figure 1. The study area (Budhigandaki basin).

mountainous high elevation basin because of significant snowmelt contribution to the runoff in these basins (Martinec et al. 2008). Several available rainfall-runoff hydrological models include snowmelt runoff modeling also for daily streamflow simulation in snowfed basins (Guo et al. 2015). The hydrological models with provision of both rainfall-runoff and snowmelt runoff simulation become more useful in the mountainous basins and many such hydrological models have been used to simulate the streamflow in these regions in different parts of the world (Yilmaz et al. 2012; Gyawali and Watkins 2013; Rezaeianzadeh et al. 2013; Joo et al. 2014; Pokhrel et al. 2014; Azmat et al. 2016). However, such studies are lacking in high altitude inaccessible snow dominated mountainous areas of Nepal (Pokhrel et al. 2014). This study is, therefore, undertaken to model the streamflow in snow dominated Budhigandaki catchment in Nepal using HEC-HMS (USACE 2015) and SRM model (Martinec 1975; Martinec et al. 2008) to assess the performance of these models in simulating rainfall/snowmelt-runoff for the catchment. The outcome of this study would be useful in understanding hydrological response of similar ungauged rivers in mountainous region originating from Himalayas.

\section{Description of the study area}

The Budhigandaki river basin is one of the major tributaries of Trishuli River in Nepal and the
Trishuli River is a major tributary of Gandaki River, which ultimately meets with Ganges in India. The total catchment area of the Budhigandaki River up to its confluence with Trishuli River is $5005 \mathrm{~km}^{2}$; however, the gauging station on the river is located upstream of confluence at Arughat bazaar. The catchment area of Budhigandaki at Arughat bazaar $\left(=3872.38 \mathrm{~km}^{2}\right)$ has been taken up for this study. The location of study catchment and its drainage network is shown in figure 1 . The study area is situated in central northern part of Nepal between latitude $28^{\circ} 00^{\prime}$ and $29^{\circ} 00^{\prime} \mathrm{N}$ and longitude $84^{\circ} 30^{\prime}$ and $85^{\circ} 15^{\prime} \mathrm{E}$. Out of $3872.38 \mathrm{~km}^{2}$ of catchment area, about $44 \%$ of the area lies in China and the remaining in Nepal. The elevation of the study area varies from $479 \mathrm{~m}$ at gauging station to $8147 \mathrm{~m}$ at the peak of the watershed from where Budhigandaki originates. So, the Budhigandaki catchment covers the area from permanently snow covered high Himalayan peak in the north to the green forest hills in the south. Due to wide range of elevation, the climate in the catchment changes from tropical (below $1000 \mathrm{~m}$ in altitude) to sub-tropical zone (1000-2000 m), temperate zone $(2000-3000 \mathrm{~m})$, subalpine zone $(3000-4000 \mathrm{~m})$ and alpine zone $(4000-5000 \mathrm{~m})$. Above $5000 \mathrm{~m}$, the area has permanent snow, no human habitation exists, and even no seasonal use is there.

The monsoon originated in the Bay of Bengal, which moves along the south bank of the Himalayas, is the main cause of rainfall in the region 
during monsoon season that on average lasts from June to the end of September. Therefore, the rainfall decreases from east to west in the region. The study area receives around $80 \%$ of the annual rainfall during the monsoon period. Rainfall intensities are varied throughout the basin with minimum intensity at the upstream part and maximum intensity at the downstream part of the basin. The catchment area experiences short winter monsoon between November and February. Relative humidity reaches maximum during the monsoon season. The Himalayan zone contributes to the streamflow in the dry season by snow and ice melt. The Central Mahabharata zone, which account for the major part of the catchment, is rain fed and contribute mostly to the flow in the monsoon season. In terms of vegetation, altitude also plays a significant role. Below $1200 \mathrm{~m}$, the dominant form of vegetation consists of tropical and subtropical rain forest.

\section{Model description}

\subsection{HEC-HMS model}

Hydrologic Engineering Centre-hydrological modeling system (HEC-HMS) of United States Army Corps of Engineer (USACE) is a very flexible and efficient hydrological model for simulation of rainfall-runoff process from dendritic watershed. HEC-HMS has a wide range of capabilities for conducting hydrological simulation through several simple modules to represent different component of hydrological cycle. The selection of appropriate model for each component depends upon the different conditions, experience of the modeler, and purpose of the modeling and availability of input data.

HEC-HMS model setup has four main model components: basin model, metrological model, control specification and input data. HEC-HMS provides different methods namely deficit constant, initial and constant, exponential, Green-Ampt, SCS (Soil Conservation Service) Curve Number, Soil Moisture Accounting and Smith-Parlange model for simulation of infiltration losses. An assortment of seven different methods namely Clark unit hydrograph, Kinematic wave, modified Clark, SCS unit hydrograph, Snyder unit hydrograph, user-specified S-hydrograph and unit hydrograph are available for transforming the excess precipitation into surface runoff. Similarly for routing of the generated surface runoff, HEC-HMS includes six different methods namely Kinematic wave, Lag, Modified pulse, Muskingum, Muskingum-conge, and Straddle stagger methods and also have several optional methods to estimate base flow, evapotranspiration, interception, depression storage, channel losses, etc. To account the component of snowmelt runoff in hydrological simulation, HEC-HMS model has incorporated the simple temperature index method based on degree-day approach (USACE 2015).

\subsection{SRM model}

The Snowmelt Runoff Model (SRM) was developed by Martinec (1975) at the Swiss Snow and Avalanche Research Institute. This model is mainly used in daily streamflow forecast and simulation in mountainous basins having snowmelt as a major component of runoff. Most recently, the model has also been used to study the impact on seasonal snow cover and runoff due the effect of changing climate (Martinec et al. 2008). The SRM also successfully underwent tests by the World Meteorological Organization (WMO) with regard to runoff simulation (WMO 1986).

\subsubsection{Model structure}

Each day, the model computes the runoff generated from rainfall and snowmelt separately and is added to the calculated recession flow to give the daily discharge from the basin. Total daily discharge from the basin is calculated according to the following equation

$$
\begin{aligned}
Q_{n+1}= & {\left[C_{s n} a_{n}\left(T_{n}+\Delta T_{n}\right) S_{n}+C_{r n} P_{n}\right] } \\
& \times \frac{A \cdot 10000}{86400}\left(1-K_{n+1}\right)+Q_{n} K_{n+1}
\end{aligned}
$$

where $Q=$ average daily discharge $\left(\mathrm{m}^{3} / \mathrm{s}\right) ; C_{s}=$ runoff coefficient for snowmelt; $C_{r}=$ runoff coefficient for rainfall; $a=$ degree day factor $\left(\mathrm{cm}^{\circ} \mathrm{C}^{-1} \mathrm{~d}^{-1}\right)$; $T=$ number of degree days $\left({ }^{\circ} \mathrm{Cd}\right) ; \Delta T=$ adjustment by temperature lapse rate when extrapolating the temperature for the different elevation zones $\left({ }^{\circ} \mathrm{Cd}\right) ; S=$ ratio of the snow covered area to the total basin area; $P=$ runoff depth formed by precipitation $(\mathrm{cm}) ; A=$ area of the basin or elevation zone $\left(\mathrm{km}^{2}\right) ; K=$ recession coefficient indicating the decline of discharge in a period without snowmelt or rainfall; $n=$ sequence of days during the discharge computation period; and 
$10000 / 86400$ is conversion from runoff depth to discharge.

\section{Data acquisition and analysis}

\subsection{Spatial data}

Digital elevation model (DEM) of the study area having resolution 90 by $90 \mathrm{~m}$ was downloaded from http://earthexplorer.usgs.gov/. Similarly, satellite derived Moderate Resolution Imaging Spectroradiometer (MODIS) Snow Cover data both for MYD10A2 and MOD10A2 from aqua and terra satellite were downloaded from https://reverb. echo.nasa.gov/reverb/. The DEM of the study area is presented in figure 2 .

\subsection{Hydro-meteorological data}

The hydro-metrological data such as precipitation, discharge and temperature, have been obtained from the Department of Hydrology and meteorology, Kathmandu, Nepal. There is no temperature station within the basin so the temperature station (CHAME) closer to the basin has been taken as the reference temperature station for this study. The locations of the hydro-meteorological stations is shown in figure 2. Preliminary analysis of rainfall data revealed that the observed rainfall series contains several missing records. However, for application of continuous simulation model require continuous series of rainfall data. The gap filling of missing data in rainfall series have been carried out by filling values at missing places of observed rainfall data with bias corrected APHRODITE's (Asian Precipitation-Highly Resolved Observational Data Integration toward Evaluation) data.

The relative biasness in APRODITE data has been calculated by using the following (Guo et al. 2015) equation

$$
R B=\frac{\sum_{i=1}^{N}\left(A_{i}-G_{i}\right)}{\sum_{i=1}^{N}\left(G_{i}\right)}
$$

where $A=$ APHRODITE data, $G=$ observed rain gauge data, and $R B=$ relative biasness.

\subsection{Elevation zoning and preparation of elevation curve of the basin}

The main purpose of elevation zoning of the basin is to closely represent the altitudinal variations of climatic variables and hydrological parameters such

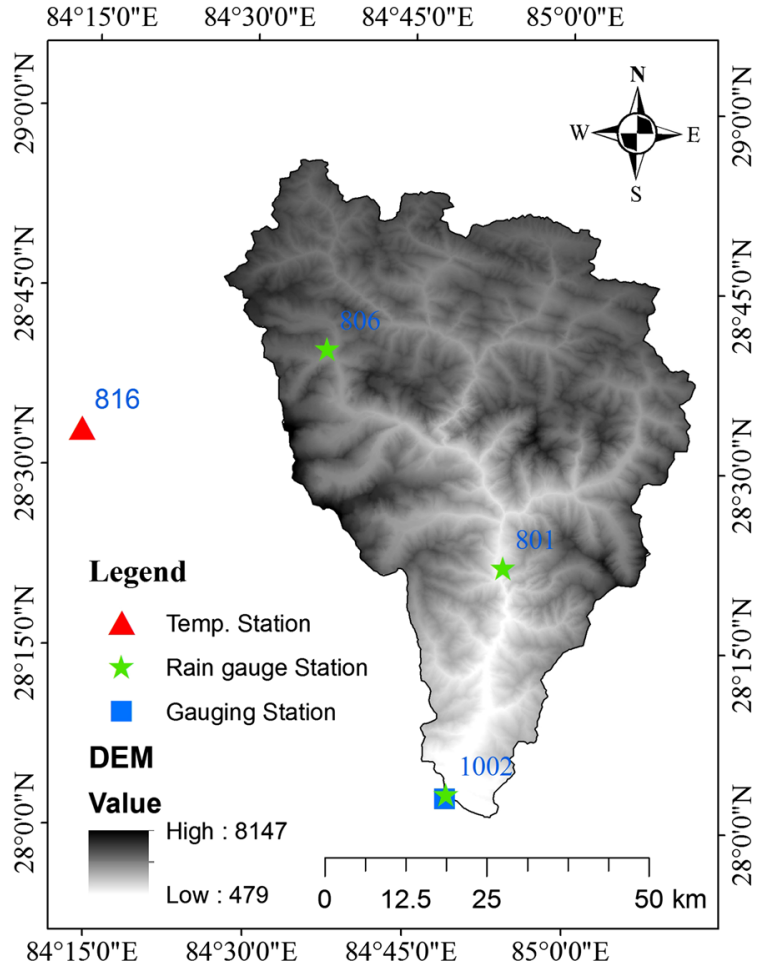

Figure 2. DEM of Budhigandaki basin with hydro-meteorological stations.

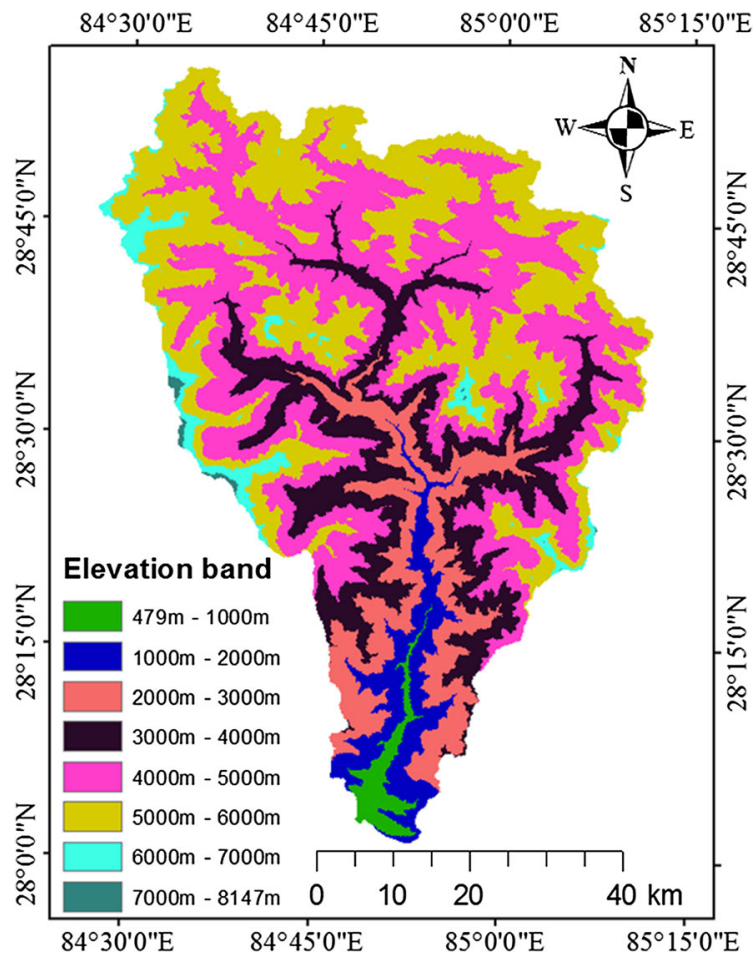

Figure 3. Classified DEM of Budhigandaki basin showing elevation bands.

as temperature, snow cover area, precipitation, degree day factor, etc., in SRM model. The basin has been divided into eight elevation zones of 


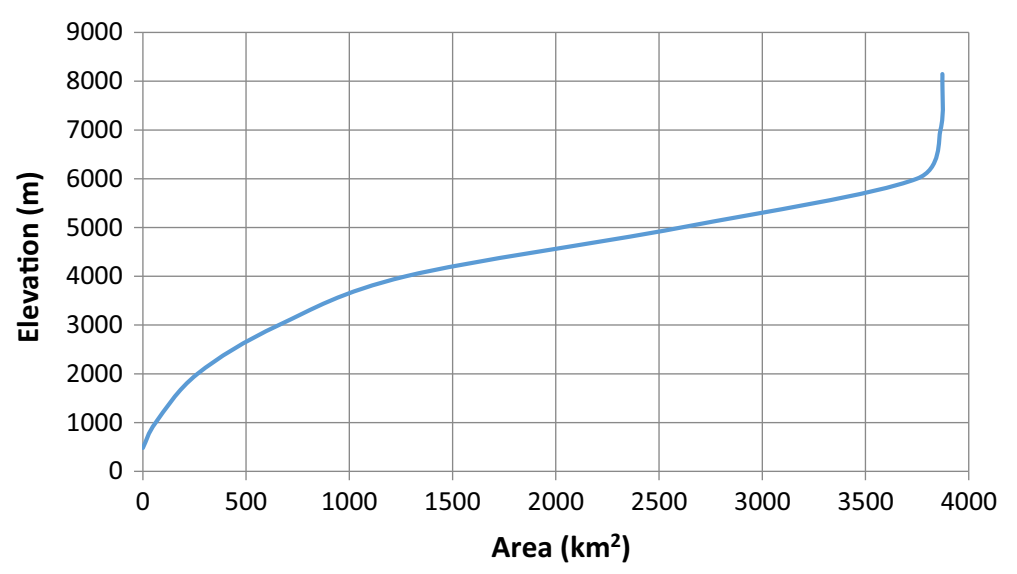

Figure 4. Hypsometric curve of Budhigandaki basin.

Table 1. Areal weight of rain gauge stations on the basis of area of elevation band for whole basin.

\begin{tabular}{llcc}
\hline $\begin{array}{l}\text { Rain gauge } \\
\text { station }\end{array}$ & $\begin{array}{l}\text { Elevation } \\
\text { band }(\mathrm{m})\end{array}$ & $\begin{array}{c}\text { Area of elevation } \\
\text { band }\left(\mathrm{km}^{2}\right)\end{array}$ & $\begin{array}{c}\text { Areal } \\
\text { weight }\end{array}$ \\
\hline 1002 & $479-4000$ & 2474.72 & 0.33 \\
801 & $4000-6000$ & 1273.68 & 0.64 \\
806 & $6000-8147$ & 123.98 & 0.03 \\
& Total & 3872.38 & 1.00 \\
\hline
\end{tabular}

around $1000 \mathrm{~m}$ elevation interval as shown in figure 3. The area elevation curve for Budhigandaki basin is shown in figure 4 , which indicate that more than $80 \%$ of the basin area is higher than 3000 $\mathrm{m}$ above mean sea level (amsl). The area elevation curve is mainly used to derive the hypsometric mean elevation for each elevation zone and shows the basin topographical characteristics.

\subsection{Estimation of basin average rainfall}

As mentioned earlier, the study basin lies in a mountainous terrain and proper representation of basin average precipitation is important due to large-scale variability of precipitation owing to orographic effects with elevation. Preliminary analysis of rainfall data collected at different rain gauge stations located at different elevations clearly indicate variability of rainfall with elevation. Therefore, for representing basin average precipitation, the study basin has been divided into different elevation bands and the areal weightage of rain gauge station have been computed based on the area of elevation band on the basis of its proximity to the respective elevation band (Jain et al. 2010). Areal weight of different rain gauge station and elevation band represented by a rain gauge station is given in table 1. Runoff coefficients calculated by using average basin rainfall from this method were found satisfactory with values ranging from 0.65 to 0.81 with average value of 0.73 . Therefore, the precipitation input in both HEC-HMS and SRM models have been given elevation band wise.

\subsection{Estimation of temperature lapse rate}

Temperature is a very important climatic variable in both HEC-HMS and SRM models to estimate snowmelt runoff from the basin. Realistic representation of temperature lapse rate for a basin especially in mountainous region is a challenging task due to the lack of adequate number of temperature observation stations (Sharma et al. 2015). In the present study, due to non-availability of sufficient temperature observation network in the study area, average annual temperature of the available stations at different elevations in the region have been used to assess temperature lapse rate. Relation between temperature and elevation of the observing station has been developed as shown in the figure 5. Fitted linear relation between temperature and elevation in the region indicate temperature lapse rate of $-0.541^{\circ} \mathrm{C}$ for 100 rise in elevation and the same has been used in present study. The study catchment does not have any temperature observation station within its 


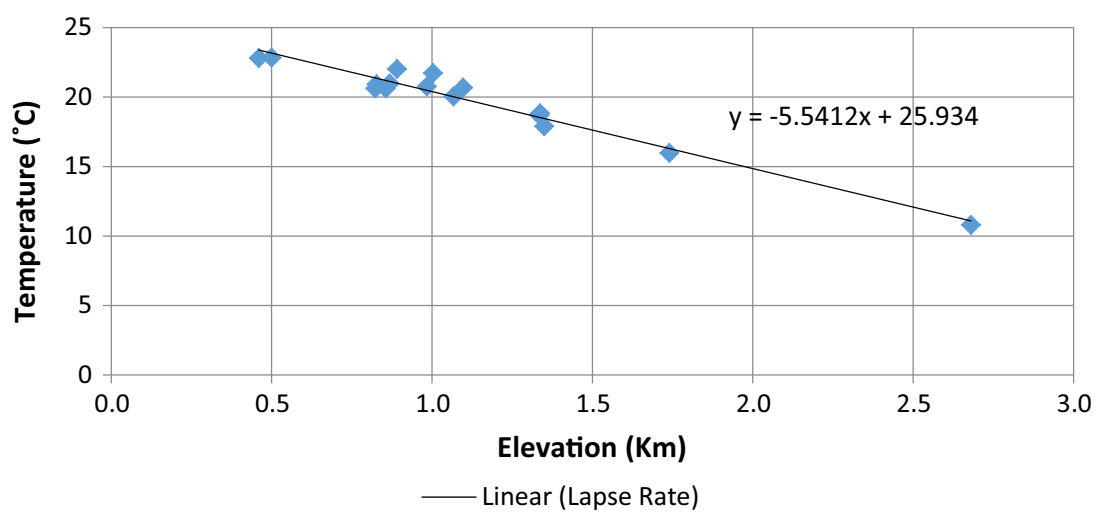

Figure 5. Average annual temperature vs. elevation.

boundary, therefore to derive temperature at different elevation zones using computed temperature lapse rate, the closest temperature station (CHAME) from the basin has been considered as the reference temperature station.

\subsection{Snow cover mapping of the study area}

MODIS snow cover products, freely available at National Snow and Ice Data Centre have been used for snow cover mapping of the study area. MODIS products are available as classified images based on normalized difference snow index (NDSI) including other test criteria. MODIS snow cover and icemapping algorithm uses the MODIS bands taken from visible to infrared portion of the spectrum. The snow has high reflectance between visible and mid infrared region of the spectrum. MODIS band$4(0.545-0.561)$ and band-6 (1.628-1.652) are used for calculation of NDSI (Hall et al. 2002). NDSI is given by as the ratio of difference of bands 4 and 6 to the sum of bands 4 and 6 .

Two types of MODIS products, MODIS Terra (MODIS/Terra Snow Cover 8-Day L3 Global 500 m SIN Grid V005) and MODIS Aqua (MODIS/Aqua Snow Cover 8-Day L3 Global 500 m SIN Grid V005) of version 5 were downloaded. The MODIS product downloaded for the period of 2003-2008 was then processed using ArcGIS software to extract the snow cover map of the basin one by one from each product. The snow covered area as required by SRM model for each elevation zone of the basin was derived using the snow cover map and elevation zone map of the study area. The daily snow covered area for each zone was then obtained by using linear interpolation between available snow covered areas at 8 days interval. The typical snow cover map on 01 May 2003 and

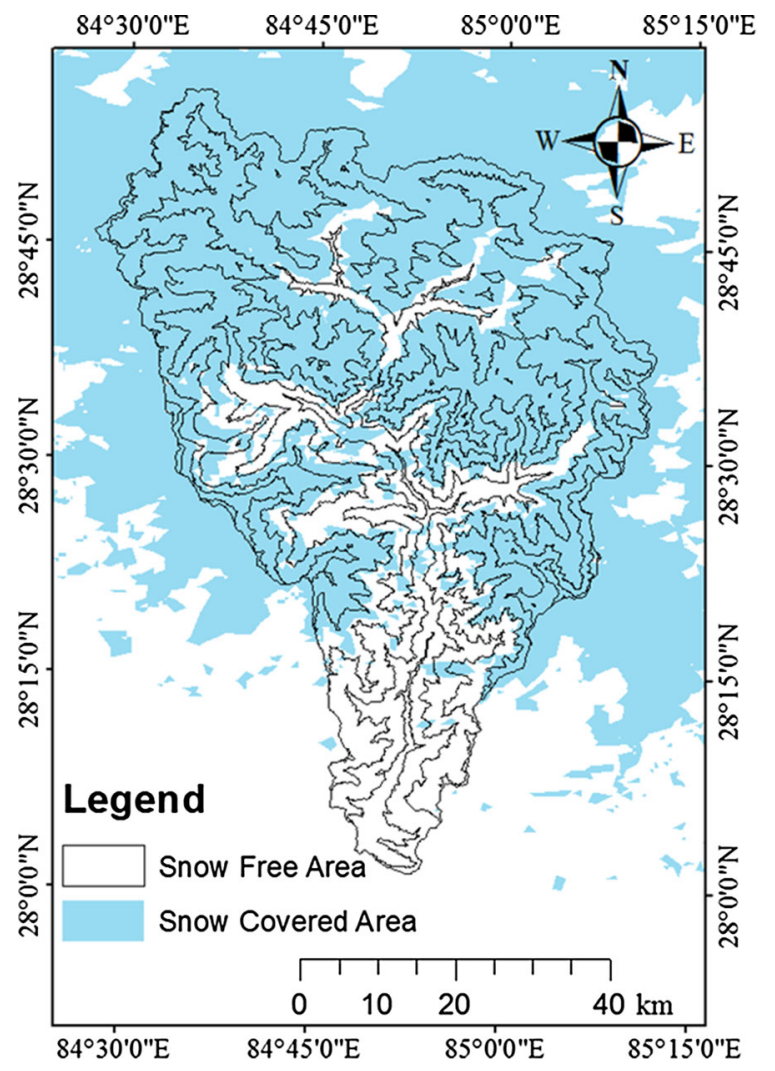

Figure 6. MODIS image of the study area (1 May, 2003).

fractional snow cover curves of the basin from 2003 to 2008 for each elevation zone above $2000 \mathrm{~m}$ elevation have been presented in the figures 6 and 7 , respectively.

\subsection{Calibration of models}

Calibration of hydrological model refers to the systematic adjustment of model parameters to get the set of parameters, which will give the best estimate of the observed streamflow. Calibration of a model is necessary because it is 


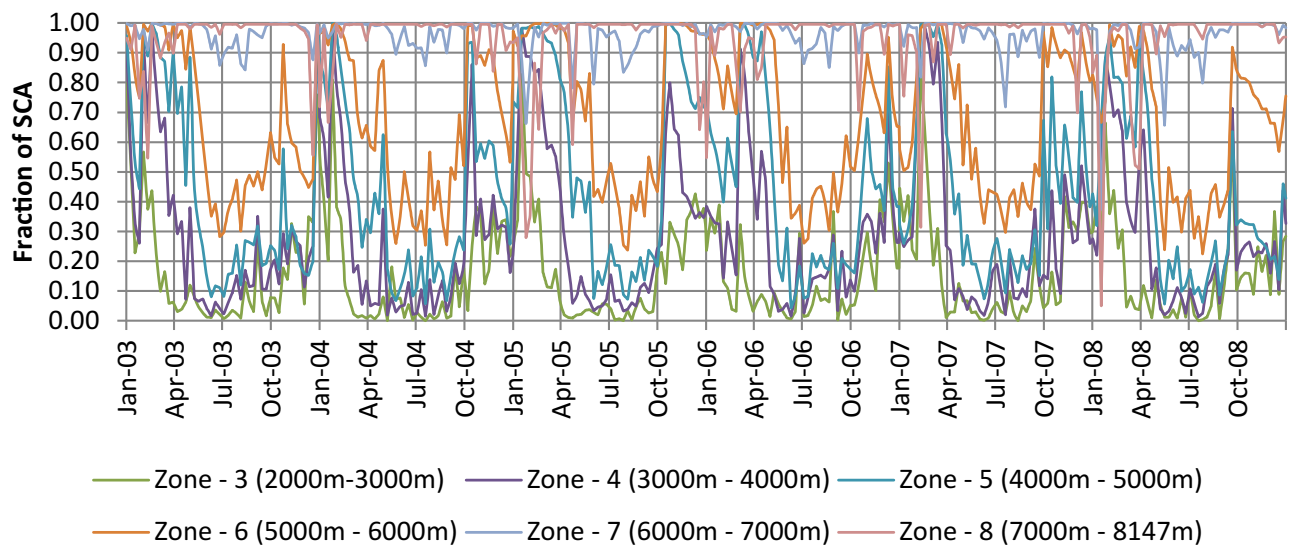

Figure 7. Snow cover curves in the Budhigandaki basin.

hard to choose values of parameters that will be representative of the entire catchment and the hydrologic processes. Moreover, the effective parameter values adopted in most of the modeling studies are lumped over the discretised sub-basin or elevation zone scale, resulting in a certain degree of uncertainty (Beven 1989; Jain and Singh 2005). A model can be considered well calibrated when the simulated discharge by the model reliably represent the observed discharge. Depending upon the features available in the model, calibration of the model can be done either by engineering judgment and manual adjustment of the parameter or by using the auto calibration tool.

Both HEC-HMS and SRM models have been calibrated using the observed runoff data of Budhigandaki watershed at Arughat gauging station (Gauge no. 445). The input variables such as precipitation, temperature and snow cover area have been used zone wise in SRM and sub-basin wise in HEC-HMS. Initial estimates of various model parameters such as runoff coefficient $(C)$, degree day factor, rainfall contributing area $(R C A)$, critical temperature ( $T$-crit), base temperature, recession coefficient $(k)$, monthly constant base flow, time of concentration, etc., have been obtained using historical data, topographic features of the basin and previous studies. These initial values of parameters have been fine-tuned by using manual and auto calibration technique available in these models. Both the models have been calibrated using the observed data for the year 2003 and validated using data for the year 2004-2008. The optimized parameters for HEC-HMS, snowmelt parameter for HEC-HMS and optimized parameter for SRM are presented in tables $2-4$, respectively.

\section{Results and discussion}

\subsection{Evaluation of models}

The performance of both the models used in this study have been evaluated using three well known statistical evaluation indices; Nash-Sutcliffe efficiency (NSE), coefficient of determination $\left(R^{2}\right)$ and percentage error in volume $(\mathrm{PEV})$. Table 5 shows the value of NSE, $R^{2}$ and $\mathrm{PEV}$ for the calibration and validation period obtained from both the models.

The NSE developed by Nash and Sutcliffe in 1970 ranges from $-\infty$ to 1 . NSE value ' 1 ' indicates the optimal value and ideal condition. Value ranging from 0 to 1 are generally acceptable for performance and value less than 0 indicates that mean of observed data gives the better estimation than simulated result. In general model, result are taken satisfactory if NSE value ranges from 0.5 to 0.65 , good 0.65 to 0.75 , and very good for greater than 0.75 (Moriasi et al. 2007). It can be seen from table 5 that the NSE values are 0.778 and 0.944 for HEC-HMS and SRM model, respectively for calibration period indicating good calibration of both models. Similarly, for validation period the value of NSE for HEC-HMS model varies from 0.612 to 0.871 with an average value of 0.773 and for SRM model, the value of NSE varies from 0.751 to 0.866 with an average value of 0.811 during validation period. Based on NSE criteria, performance of both the model has been rated as very good.

The coefficient of determination $\left(R^{2}\right)$, which is square of Pearson's correlation coefficient $(r)$ indicates the degree of co-linearity between simulated and observed data. As the correlation coefficient varies from -1 to +1 , the coefficient of 


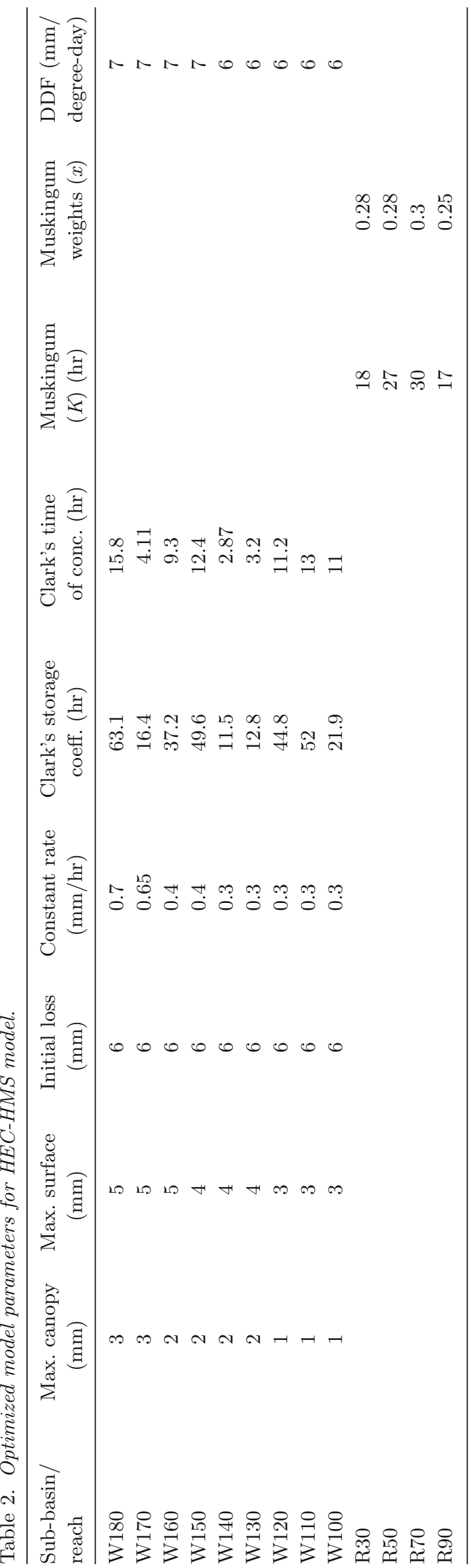

determination varies from 0 to $1 . R^{2}$ shows the proportion of variance in observed data explained by the model. The value of $R^{2}$ varies from 0 to 1 . Higher value of $R^{2}$ indicates less error in variance, generally value greater than 0.5 are taken acceptable (Moriasi et al. 2007). In this study, as shown in the table 5 , the values of $R^{2}$ for HEC-HMS and SRM model are 0.785 and 0.944 for calibration period and average value of 0.777 and 0.816 for validation period, respectively. The $R^{2}$ values obtained for both models shows the very good simulation by the models.

Percentage error in volume (PEV) indicates the average tendency of simulated discharges to be above or below the measured counterparts. The optimal value of $\mathrm{PEV}$ is 0 . The positive value of PEV shows that the model has underestimated streamflow, whereas negative value shows overestimation. PEV values within $10 \%$ are considered very good, 10-15\% good, 15-25\% satisfactory and unsatisfactory above 25\% (Moriasi et al. 2007). In this study, in calibration period $\mathrm{PEV}$ values of -1.84 and $-0.3 \%$ have been obtained from HEC-HMS and SRM model, respectively, whereas for validation period the PEV values varied from -1.78 to $9.16 \%$ for HEC-HMS and -1.84 to $+4.3 \%$ for SRM model. This result also shows that both the models have given the very good simulation.

Graphical comparison between observed and model simulated discharge is useful in comparison of matching of peaks of observed and simulated values as well as overall visual match. For graphical evaluation of the model results, simulated discharge from both the models and observed discharge have been plotted together against the elapsed time and shown in figures 8 and 9 for HEC-HMS and SRM model, respectively. The plots show good agreement between model simulated and observed discharge for both the models for most of the year of simulation except some exceptional short time period. Close scrutiny of figures 8 and 9 indicate that simulated discharges from both models have shown very good agreement with the corresponding observed discharge for almost all peaks and both rising and recession portion of simulation period; however, some peaks simulated by HEC-HMS model are overestimated as compared to the SRM model. Overall trend of simulated discharge from both the models have followed the observed discharge pattern satisfactorily with both the models have reproduced most of the peaks and the simulated discharge from two models are also matching in general to each other. In year 
Table 3. Snowmelt parameters for HEC-HMS model.

\begin{tabular}{lll}
\hline Sl. no. & \multicolumn{1}{c}{ Parameters } & Value \\
\hline 1 & PX temperature $\left({ }^{\circ} \mathrm{C}\right)$ & 0.5 \\
2 & Base temperature $\left({ }^{\circ} \mathrm{C}\right)$ & 0 \\
3 & Wet meltrate $\left(\mathrm{mm} .{ }^{\circ} \mathrm{C}^{-1} \cdot\right.$ day $\left.^{-1}\right)$ & 5.5 \\
4 & Degree day factor $\left(\mathrm{mm} .{ }^{\circ} \mathrm{C}^{-1} \cdot\right.$ day & -1 \\
5 & Rain rate limit $(\mathrm{mm} /$ day $)$ & $6-7$ \\
6 & ATI meltrate coefficient & 0.6 \\
7 & Cold limit $(\mathrm{mm} /$ day $)$ & 0.98 \\
8 & ATI coldrate coefficient & 1.2 \\
9 & Water capacity $(\%)$ & 0.5 \\
10 & Ground melt $(\mathrm{mm} /$ day $)$ & 3 \\
\hline
\end{tabular}

Table 4. Optimized model parameters for SRM model.

\begin{tabular}{|c|c|c|}
\hline Sl. no. & Parameter & Value \\
\hline 1 & Degree day factor $\left(\mathrm{mm} \cdot{ }^{\circ} \mathrm{C}^{-1} \cdot\right.$ day $\left.^{-1}\right)$ & $0.28-0.75$ \\
\hline 2 & Runoff coefficient for rain & $0.6-0.705$ \\
\hline 3 & Runoff coefficient for snow & $0.58-0.685$ \\
\hline 4 & Temperature lapse rate $\left({ }^{\circ} \mathrm{C}\right.$ per $100 \mathrm{~m}$ rise $)$ & -0.5541 \\
\hline 5 & Critical temperature $\left({ }^{\circ} \mathrm{C}\right)$ & 1 \\
\hline 6 & Rainfall contributing area & 0,1 \\
\hline 7 & Lag time & 13.45 \\
\hline 8 & Recession constant (X) & $1.286-1.381$ \\
\hline 9 & Recession constant (Y) & $0.075-0.095$ \\
\hline
\end{tabular}

Table 5. Summary of results from HEC-HMS and SRM model.

\begin{tabular}{lcccccrrr}
\hline & \multicolumn{2}{c}{$R^{2}$} & & \multicolumn{2}{c}{ NSE } & & \multicolumn{2}{c}{ PEV } \\
\cline { 2 - 3 } Year & HEC-HMS & SRM & & HEC-HMS & SRM & & HEC-HMS (\%) & SRM (\%) \\
\hline 2003 & 0.785 & 0.944 & & 0.778 & 0.944 & & -1.83 & -0.30 \\
2004 & 0.779 & 0.866 & & 0.779 & 0.863 & & 2.35 & -0.26 \\
2005 & 0.779 & 0.781 & & 0.776 & 0.778 & & 3.51 & 1.37 \\
2006 & 0.836 & 0.870 & & 0.830 & 0.866 & & -1.78 & 4.30 \\
2007 & 0.614 & 0.796 & & 0.612 & 0.795 & & 0.71 & -1.84 \\
2008 & 0.878 & 0.769 & & 0.871 & 0.751 & & 9.16 & 2.29 \\
Calibration & 0.785 & 0.944 & & 0.778 & 0.944 & & -1.83 & -0.30 \\
Validation & 0.777 & 0.816 & & 0.773 & 0.811 & & 3.50 & 2.01 \\
\hline
\end{tabular}

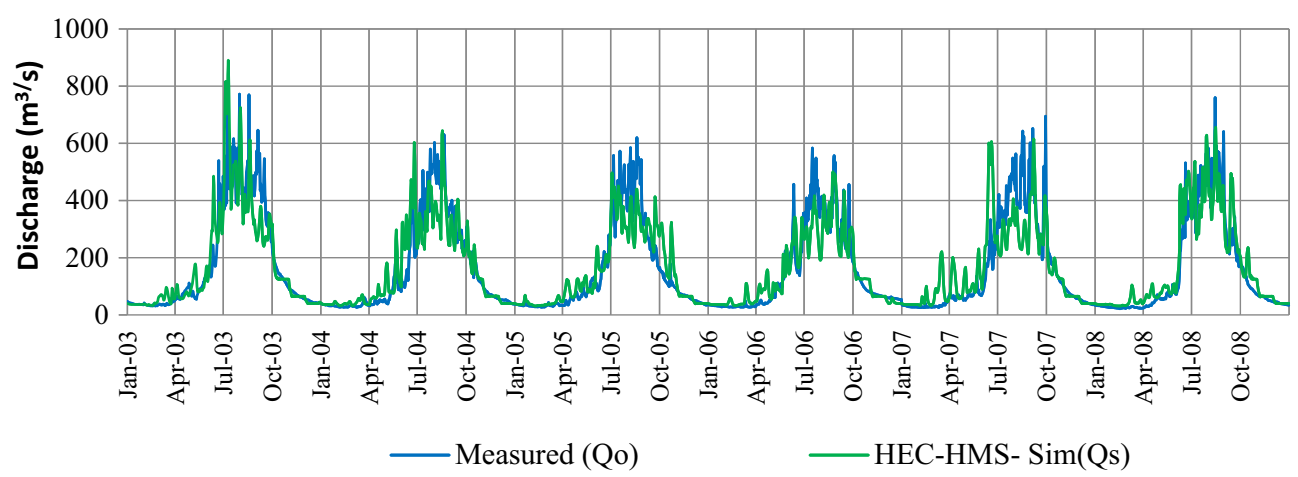

Figure 8. Comparison of observed and HEC-HMS simulated hydrographs. 


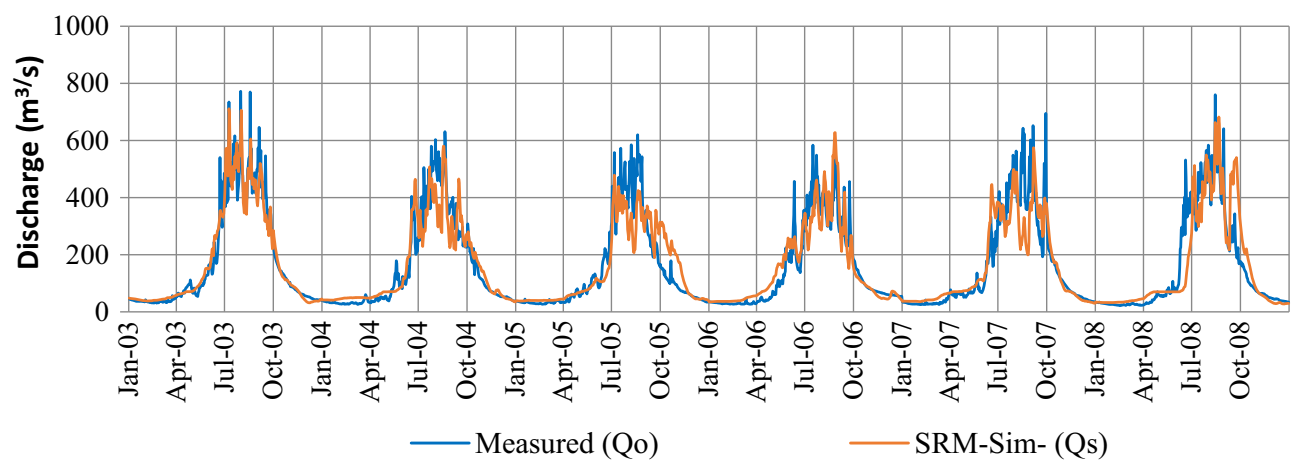

Figure 9. Comparison of observed and SRM simulated hydrographs.

2005, for the period of July-September, there is an underestimation of flow and after September to mid-November, there is overestimation of the flow by both the models, but the simulated discharge from the models have good matching to each other. Relatively poor performance for year 2005 may be attributed to possible observational errors either in observed precipitation or in discharge data for the above mentioned period. Similarly in the year 2008, the simulated discharge by SRM model has started to increase from the 3rd week of June only, whereas simulated discharge from HEC-HMS and observed discharge has started to increase from the first week of June. Since SRM model has more sensitivity to degree day factor than HEC-HMS model, it is suspected that there is some error in temperature measurement at that period and snowmelt couldn't start so that simulated discharge seemed underestimated.

\subsection{Sensitivity analysis}

Hydrological modeling procedure involves modeling of one or more phase of hydrological cycle by simplified system. Although, the hydrological model should closely represent the different hydrological process, the final model becomes only an approximate representation of the process. The sensitivity analysis of hydrological model can be used as a tool to understand the correspondence of the hydrological process being modeled and the model itself (Richard 1972). Sensitivity of model parameters is also useful in verification of the hydrological model. There may be various set of model parameters, which would give the same result as another set, in this regard the sensitivity analysis gives a better idea about how good are the optimized model parameters and a mean of ranking the model parameter as per their relative importance. Some parameters may be very sensitive and may have more influence on the simulated result, whereas another parameter may have less effect. So, it is very essential to determine the sensitivity of all the parameter used in the model and fix the most sensitive parameters. The accuracy of the model simulation results largely depends upon the precise estimation of most sensitive parameter of the model. The sensitivity analysis is carried out by changing the one parameter at a time while keeping all the remaining parameters same and the effect on simulation is observed.

For this study, in both HEC-HMS and SRM model all the parameters used have been tested for sensitivity analysis. Each parameter in the model was varied from +50 to $-50 \%$ from the optimized parameter value with an increment step of $\pm 10 \%$ and simulation was run for each change in the value of parameter. The percentage change in the simulated runoff was then plotted against percentage change in the model parameter values.

For both the models sensitivity analysis was carried out for the calibration year 2003. Sensitivity of six selected parameters for HEC-HMS and six parameters of SRM have been carried out by changing one parameter at a time keeping value of all the remaining parameters same as obtained through calibration and the effect on simulation discharge has been noted for each alteration of the value of parameters. Value of parameters have been varied from +50 to $-50 \%$ of the optimized value of parameter with an increment step of $\pm 10 \%$ and effect on model simulated discharge with each alteration of parameter value have been noted. The PEV and NSE for HEC-HMS model and PEV and $R^{2}$ for SRM model have been plotted for each parameter within range of +50 to $-50 \%$ deviation 


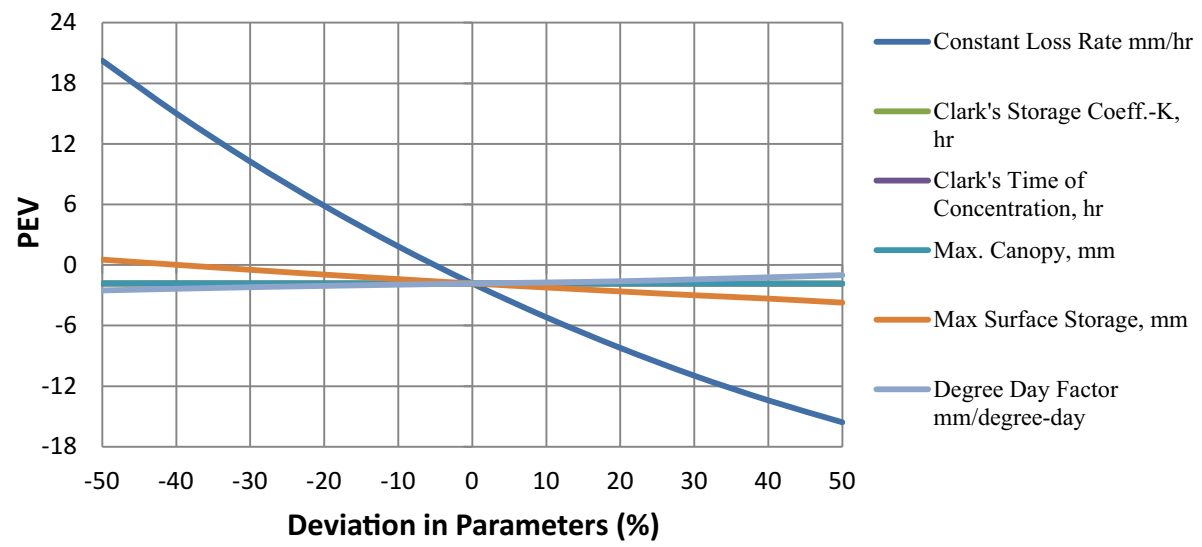

Figure 10. Sensitivity analysis on PEV for HEC-HMS model.

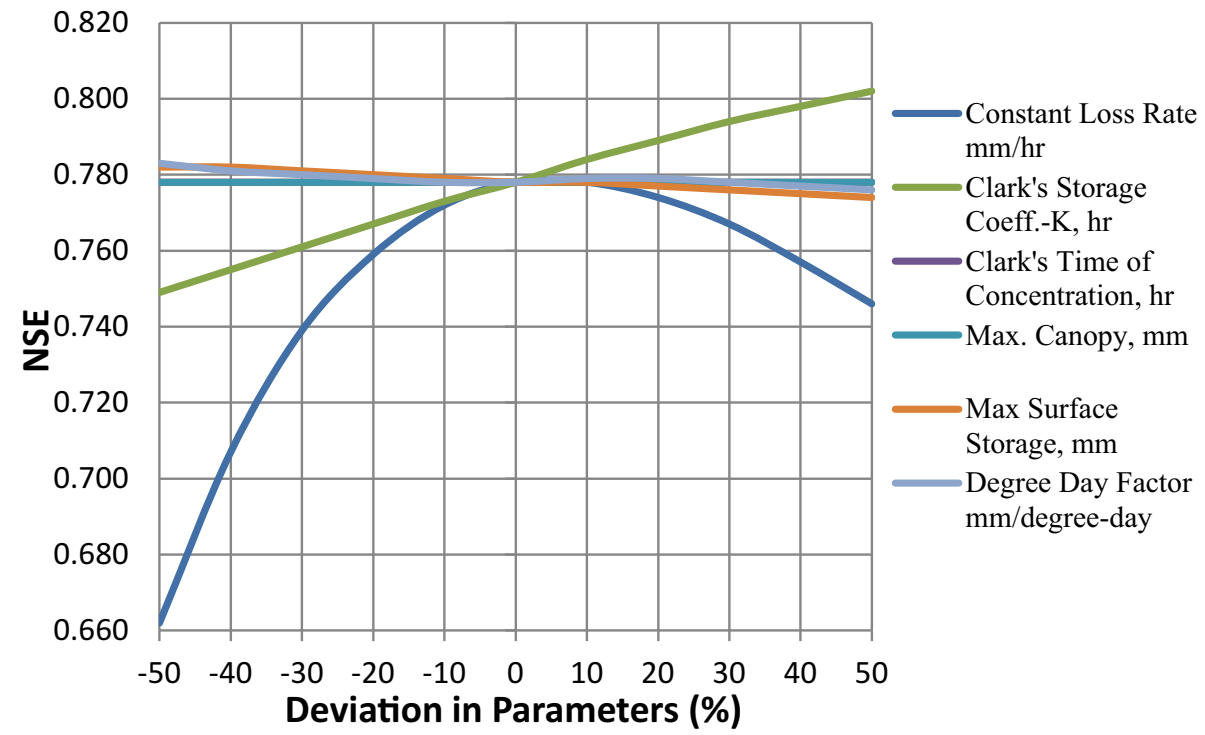

Figure 11. Sensitivity analysis on NSE for HEC-HMS model.

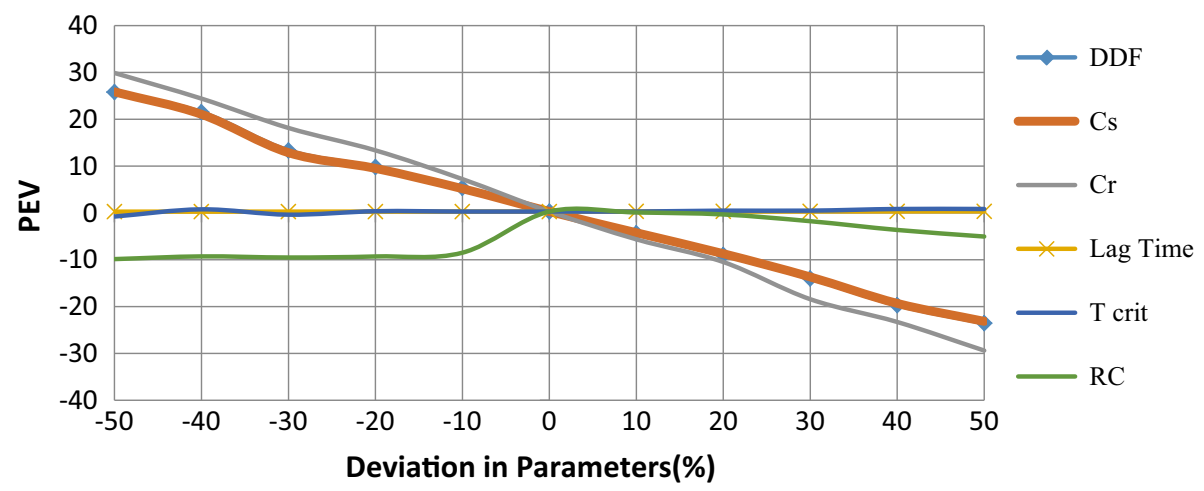

Figure 12. Sensitivity analysis on PEV for SRM model.

from optimized parameter and are presented in figures 10-13, respectively.

Sensitivity analysis reveals that constant loss rate for HEC-HMS and runoff coefficient $\left(C_{r}\right)$ for SRM model are the most sensitive parameters. For
HEC-HMS model, a -50 to $+50 \%$ change in the value of constant loss rate parameter resulted in variation in $\mathrm{PEV}$ in the range from +20.25 to $-15.58 \%$ and variation in the value of NSE in the range from 0.662 to 0.746 , whereas for SRM, 


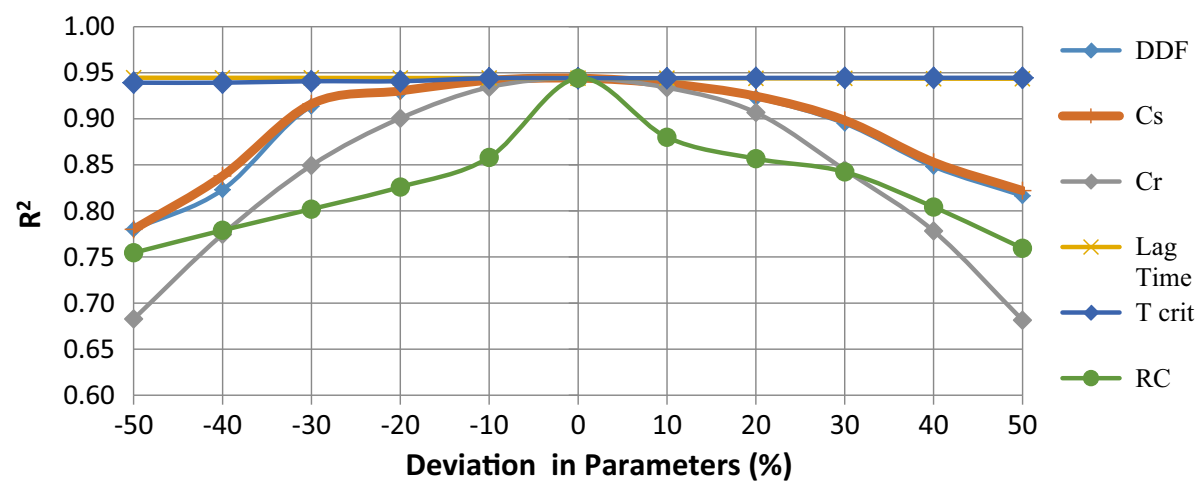

Figure 13. Sensitivity analysis on $R^{2}$ for SRM model.

variation in the value of runoff coefficient $\left(C_{r}\right)$ between -50 and $+50 \%$ resulted in change in PEV between +29.88 and $-29.37 \%$ and variation in $R^{2}$ between 0.683 and 0.682 .

\subsection{Discussion of results}

Close scrutiny of snow curves presented in figure 7 reveals that the fractional areal extent of snow cover increases toward the higher elevation zones and snowmelt mainly occurs from the elevation zone 3 to 6 , i.e., elevation 2000-6000 m amsl. Zones 7 and 8 , which are above the elevation of $6000 \mathrm{~m}$ do not contribute to significant snowmelt as the fractional snow cover area remains almost same throughout the year in these zones. Further, as can be seen from figure 7 , the snow cover area fraction decline sharply from March to June every year indicating occurrence of major snowmelt in the basin from March to June. The snow starts accumulating again from September in the basin each year.

Visual comparisons of observed and simulated discharge from both the models presented in the figures 8 and 9 for the period 2003-2008 shows good agreement between observed and simulated runoff for both calibration and validation periods. Both the models have reproduced most of the runoff peaks with reasonable accuracy except for overestimation of few peaks by HEC-HMS as compared to those simulated using SRM. In the year 2005, for the period of July-September, there is underestimation of flow and after September to mid-November there is overestimation of the flow by both the models but the simulated discharge from two models have good matching to each other. Relatively poor performance for the year 2005 may be attributed to the possible observational uncertainties either in observed precipitation or in discharge data. In general, agreement between observed and simulated discharge by both models could be rated as very good; however, quantitative statistics of simulation results indicate slightly better simulation by SRM model.

Sensitivity analysis reveals that loss rate for HEC-HMS model and runoff coefficient (rain) for SRM model are the most sensitive parameters, respectively. The degree-day factor, which is a common parameter for snowmelt simulation in both HEC-HMS and SRM model, was found more sensitive in SRM model than in HEC-HMS model. In HEC-HMS model, the use of monthly constant base flow derived from historical monthly average hydrograph using variable slope base flow separation method might be the main cause to have less sensitivity of the model in degree-day factor because the major portion of snowmelt runoff is already included in the base flow.

It is pertinent here to discuss potential limitations of the present study. As mentioned earlier, the study area is located in very high altitude and very few hydro-meteorological stations are available in the study area. Also, available daily precipitation data in each station were having lots of gap and these have been suitably filled using APHRODITE data. In addition, the MODIS data having resolution $500 \mathrm{~m}$ was used for estimating the snow covered area in the basin but in mountainous region within $500 \mathrm{~m}$ distance, there is large topographical variation, so the estimated snow covered area may deviate slightly from the actual snow covered area.

\section{Conclusions}

Estimation of streamflow is required for planning water resource projects in a river basin. Most of the river basins in the Himalayan region are ungauged and hydrological studies in these river basins are lacking in the literature. In this study, 
comparative evaluation of performance of HEC-HMS and SRM models have been carried out for simulating streamflow behavior of snowmelt dominated Budhigandaki catchment. The catchment lies at very high altitude with complex terrain in the Himalayan region with very limited observed data. Both HEC-HMS and SRM model have been successfully calibrated and validated for the Budhigandaki catchment on continuous time scale. From sensitivity analysis of parameters, constant loss rate for HEC-HMS and runoff coefficients for SRM were found to be the most sensitive parameters in the basin. The very good simulation result obtained from SRM model proved that MODIS snow cover product can be used in the study area for snow cover mapping and snowmelt runoff simulation. Analysis of change in fraction of snow cover area with time derived from MODIS data clearly indicate that the study basin experiences major snowmelt from March to June and accumulation of snow in the basin starts from September every year. A good efficiency of HEC-HMS model with initial and constant loss method showed that parameters can be well calibrated in the model with limited field information and this model can be used for the prediction of streamflow. However, comparative performance evaluation of both models based on all three evaluation criteria NSE, $R^{2}$ and PEV indicate slightly closer match between the observed and model simulated discharge by SRM model than using HEC-HMS in both calibration and validation periods. Also both the models have given good model efficiency and very less PEV values throughout the study period. So, the results obtained from both models could be categorized in very good category indicating applicability of both models for runoff simulation in the basin. Since, SRM model is simple and require less data than HEC-HMS and has also given slightly better match between observed and model simulated discharge than HEC-HMS in Budhigandaki basin, SRM model is recommended for simulation of runoff for this and other similar basins in the Himalayan region.

\section{Acknowledgements}

The first author acknowledge the financial assistance through ITEC fellowship provided by the Government of India to support his postgraduate studies at the Department of Hydrology, IIT Roorkee, India. Department of Hydrology and
Meteorology, Government of Nepal is thanked for providing hydrological and meteorological data.

\section{References}

Azmat M, Choi M, Kim T W and Liaqat U W 2016 Hydrological modeling to simulate streamflow under changing climate in a scarcely gauged cryosphere catchment; Environ. Earth Sci. 75, https://doi.org/10.1007/ s12665-015-5059-2.

Beven K 1989 Changing ideas in hydrology - the case of physically based model; J. Hydrol. 105 157-172.

Guo H, Chen S, Bao A, Hu J, Gebregiorgis A, Xue X and Zhang X 2015 Inter-comparison of high-resolution satellite precipitation products over central Asia; Remote Sens. 7 7181-7211, https://doi.org/10.3390/rs70607181.

Gyawali R and Watkins D W 2013 Continuous hydrologic modeling of snow-affected watersheds in the great lakes basin using HEC-HMS; ASCE J. Hydrol. Eng. 18 29-39, https://doi.org/10.1061/(ASCE)HE.1943-5584.0000591.

Hall D K, Riggs G A, Salomonson V V, DiGirolamo N $\mathrm{E}$ and Bayr K J 2002 MODIS snow-cover products; Remote Sens. Environ. 83(1-2) 181-194, https://doi. org/10.1016/S0034-4257(02)00095-0.

Jain M and Singh V 2005 DEM based modelling of surface runoff using diffusion wave equation; J. Hydrol. $302107-$ 126.

Jain S, Goswami A and Saraf A K 2010 Snowmelt runoff modelling in a Himalayan Basin width the aid of satellite data; Int. J. Remote Sens. 31(24) 6603-6618.

Joo J, Thomas K, Kim H and Lee H 2014 A comparison of two event-based flood models (ReFH-rainfall runoff model and HEC-HMS) at two Korean catchments, Bukil and Jeungpyeong; KSCE J. Civ. Eng. 18(1) 330-343, https:// doi.org/10.1007/s12205-013-0348-3.

Martinec J 1975 Snowmelt runoff model for streamflow forecasts; Nord. Hydrol. 6 145-154.

Martinec J, Rango A and Roberts R 2008 Snowmelt Runoff Model (SRM) User's Manual; Las Cruces: USDA Jornada Experimental Range, New Mexico State University.

Moriasi D N, Arnold J G, Van Liew M W, Bingner R L, Harmel R D and Veith T L 2007 Model evaluation guidelines for systematic quantification of accuracy in watershed simulation; Trans. ASABE 50(3) 885-900.

Pokhrel B K, Chevallier P, Andréassian V, Tahir A A, Arnaud Y, Neppel L and Budhathoki K P 2014 Comparison of two snowmelt modeling approaches in the Dudh Koshi basin (eastern Himalayas, Nepal); Hydrol. Sci. J. 59(8) 1507-1518, https://doi.org/10.1080/02626667. 2013.842282

Richard H M 1972 The role of sensitivity analysis in hydrological modeling; J. Hydrol. 18(1) 37-53.

Rezaeianzadeh M, Stein A, Tabari H, Abghari H, Jalalkamali N, Hosseinipour E and Singh V P 2013 Assessment of a conceptual hydrological model and artificial neural networks for daily outflows forecasting; Int. J. Environ. Sci. Technol. 10 1181-1192, https://doi.org/10. 1007/s13762-013-0209-0.

Sharma V, Mishra V and Joshi P 2015 Estimation of temperature lapse rate in a snowfed river basin of northwest 
Himalaya using satellite; Int. J. Multi. Res. Dev. 2(12) 477-482.

US Army Corps of Engineers 2015 Hydrologic Modelling System (HEC-HMS User's Manual); Hydrologic Engineering Centre (HEC).

World Meteorological Organization 1986 World Meteorological Organization (WMO) Intercomparison of models of snowmelt runoff (Operational Hydrology), Geneva.

Yilmaz A G, Imteaz M A and Ogwuda O 2012 Accuracy of HEC-HMS and LBRM models in simulating snow runoffs in upper Euphrates basin; ASCE J. Hydrol. Eng. 17(2) 342-347, https://doi.org/10.1061/(ASCE)HE.1943-5584. 0000442 .

Corresponding editor: RAJIB MAITY 